\title{
IMPACT OF FREIGHT TRANSPORTATION ON CD. JUÁREZ ENVIRONMENT AND REVIEW OF AERODYNAMIC DRAG REDUCTION DEVICES FOR HEAVY TRUCKS
}

\section{Impacto del transporte de carga en el ambiente de Ciudad Juárez y revisión de dispositivos de reducción de carga aerodinámica para camiones pesados}

\author{
Shehret Tilvaldyev', Uzziel Caldiño Herrera², \\ José Omar Dávalos Ramírez ${ }^{3}$, Manuel Alejandro Lira Martinez4. \\ ${ }^{1-4}$ Aeronautics Department, Universidad Autónoma de Ciudad Juárez, Mexico, \\ Email: ${ }^{1}$ shehret@uacj.mx, ${ }^{2}$ uzziel.caldino@uacj.mx, ${ }^{3}$ jose.davalos@uacj.mx, \\ ${ }^{4}$ manuel.lira@uacj.mx.
}

(Recibido Febrero 20 de 2020 y aceptado Marzo 20 de 2020)

\section{Resumen}

En la actualidad, el estudio de como disminuir las emisiones de gases de efecto invernadero de todos los sectores, incluido el transporte es muy importante. El propósito de este trabajo es estudiar el impacto ambiental del transporte de carga en Cd. Juárez y revisar los dispositivos de reducción de arrastre aerodinámico para camiones pesados para tener un mayor entendimiento de que tecnologías o prácticas pueden ser implementadas en el transporte de carga para reducir el arrastre aerodinámico sin afectar el desempeño de los vehículos.

Palabras clave: arrastre aerodinámico, dispositivos de reducción de arrastre, impacto ambiental, camiones de carga.

\begin{abstract}
Nowadays studying the ways in which greenhouse gas emissions may be reduced from all sectors of human been activities, including the transportation sector, became extremely important. The purpose of this investigation is study environmental impact of freight transportation in cd. Juarez area and review of aerodynamic drag reduction devices for heavy trucks to better understand what technologies or practices can be applied to highway tractor and trailer combinations to reduce aerodynamic drag without negatively affecting the usefulness or profitability of the vehicles.
\end{abstract}

Key words: aerodynamics drag, drag redaction devices, environmental impact, heavy tracks.

\section{INTRODUCCIÓN}

The total aerodynamic drag, depending on air viscosity (skin friction) and forms of heavy vehicles (wave and interference drag) is an irreparable loss of energy and solving of problems of reducing the total aerodynamic drag is one of the most efficient way to improve fuel consumption and to reduce emissions of heavy vehicles. Some modern technics and technologies have very high potential to reduce total drag, but the uptake is generally slowly due to requirements to return of investments, sooner. Therefore, any activities to reduce fuel consumption and emissions of heavy vehicles provide net benefits, but becoming stressful social and engineering factors.

Aerodynamics of road vehicles is a complex discipline and many specific topics beyond the scope of this research. However, some facts related to transportation Industries, especially for heavy trucks, are presented. In general aerodynamics deals with airflow around (external flow) and through (internal flow) the solid object. Analysis of heavy vehicles aerodynamics includes 
investigation of any impact on performance of heavy truck (I), its handling (II), safety (III), and comfort (IV). This research investigated only negative influence of aerodynamic drag on performance of the vehicle as a critical issue, and its effect on fuel consumption.

Heavy vehicle's engine transforming fuel energy to the engine power output, that contributing to the five main factors, shown on Table 1: Transmission, Inertia and Braking, Rolling Resistance, Supplemental Loads, and Aerodynamic Drag. Data used in Table 1 adapted from [1]. Depending on the driving environment of the vehicle (e.g. driving in city at low speed and frequently stops, or highway traffic at a constant and high speed), the contribution of the power output to these five factors varies proportionally the other, as shown in table 1. For example, in urban environments, power dissipates due to acceleration and deceleration of the vehicle; losses prevail while on the highway aerodynamic losses are dominant. Light hybrid vehicles with energy recovery systems are potentially a good solution to reduce fuel consumption in urban environments. For the environment in which most commercial goods are transported, whose aerodynamic losses disperse and cannot be recovered is the main source of energy and fuel consumption. Aerodynamic loss reduction is a significant area in which can improve fuel consumption.

Table 1. Tractor-trailer's Engine power output balance

\begin{tabular}{ccc}
\hline Main Factors & City \% & Highway \% \\
\hline Transmission & $10-15$ & $10-15$ \\
Inertia and Braking & $35-50$ & $0-5$ \\
Rolling Resistance & $20-30$ & $30-40$ \\
Supplemental Loads & $15-20$ & $2-10$ \\
Aerodynamic Drag & $10-25$ & $35-55$ \\
\hline
\end{tabular}

The percentage of power output balance for each of the five factors varies depending on the speed and type of the vehicle, since the any of effects of aerodynamics is individual. The contribution to fuel combustion due to internal losses is usually modeled as constant, and part of the acceleration / deceleration / slope can be modeled by driving environment.

It is good known that aerodynamic drag is a force resisting the movement of a solid object, and varies with the square of the relative air speed (Fig.1). Data for the graph obtained from laboratory experiments on Subsonic Wind Tunnel.

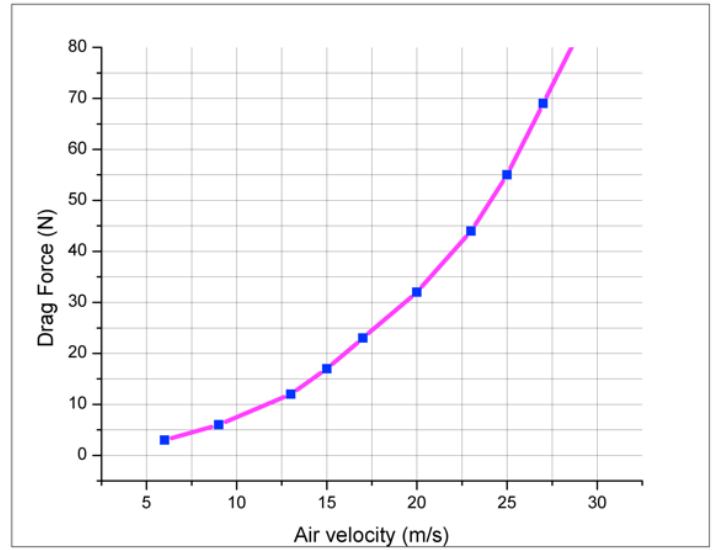

Figure 1. Variation of Drag according to Airspeed around the Tractor-trailer.

Relative air speed $\left(U_{\infty}\right)$ is speed between the vehicle and ambient air. When the vehicle moves in still air, doubling the speed of the vehicle will increases magnitude of the aerodynamic drag about four times. In the presence of earthly winds that not in accordance with the movement of the vehicle, transverse winds create a non-zero yaw angle of the wind relative to the direction of movement of the vehicle. For heavy trucks, the drag coefficient increases significantly with the yaw angle.

The drag force on a vehicle can be calculated as follows:

$F D=0.5 \rho(U \infty) 2 C D(\psi \infty) A$

Where:

FD is the Drag force;

$\rho \quad$ is the density of the ambient air; 
$U_{\infty}$ is the air speed of the object (speed relative to the surrounding air);

$\psi \infty$ is yaw-angle of the air-flow relative to the vehicle motion;

$C D$ is drag coefficient;

A is the front area of the vehicle.

In general, mechanical losses in the system linearly depend on the speed of the vehicle. At a speed of $53 \mathrm{~km} /$ $\mathrm{h}$ the power required to overcome mechanical resistance is approximately double that required for overcome aerodynamic drag. At a speed, increased up to $80 \mathrm{~km} / \mathrm{h}$, is needed power to overcome aerodynamic drag, and at speeds over $80 \mathrm{~km} / \mathrm{h}$ aerodynamic losses dominate.

In Table 2 illustrated the contribution of Aerodynamics Drag and Rolling Resistance to fuel consumption at different range of constant speeds and equal other options (i.e., without acceleration, properly inflated tires, etc.,). Data for Table 2 adapted from (2).

Table 2. Contribution of Aerodynamics Drag and Rolling Resistance to fuel consumption at different range of constant speeds of Heavy Trucks

\begin{tabular}{ccc}
\hline $\begin{array}{c}\text { Vehicle Speed, } \\
\mathbf{k m} / \mathbf{h}\end{array}$ & $\begin{array}{c}\text { Aerodynamic } \\
\text { Drag, \% }\end{array}$ & $\begin{array}{c}\text { Rolling } \\
\text { Resistence, \% }\end{array}$ \\
\hline 32 & 28 & 72 \\
53 & 33 & 66 \\
64 & 36 & 64 \\
80 & 50 & 50 \\
96 & 62 & 38 \\
105 & 67 & 33 \\
113 & 70 & 30 \\
\hline
\end{tabular}

Since aerodynamic drag is one of the sources of fuel consumption, it is important to understand its affects on total fuel consumption. At a speed of $80 \mathrm{~km} / \mathrm{h}$, a decrease in resistance of $20 \%$ will contribute to reduction in fuel consumption by about $10 \%$. Consequently, reduction in fuel consumption will reduce contamination of the air by reducing the amount of pollutant elements, which is very stressful environmental, political and social factor everywhere, and especially for the Municipalities as Juarez, Mexico.

\section{ENVIRONMENTAL IMPACT OF FREIGHT TRANSPORTATION IN MUNICIPALITY OF JUAREZ}

The Municipality of Juárez is located in northern Mexico in the State of Chihuahua. The Municipality of Juárez occupies $1.4 \%$ of the territorial extension of the State, and is located 1,120 meters above the average sea level. Demographically, Juarez is the most populous municipality in the state with $1,332,131$ inhabitants (2010), or 38.8\% of the population of the State of Chihuahua. This results in a high economic activity for which it is necessary to supply the city with raw materials, food and consumables. In addition, to its strategic geographical position adjacent to the State of Texas in the United States of America, Ciudad Juarez has positioned itself as one of the national border municipal entities, which has a high demand for the exchange of materials and goods, so the Cargo truck transit in this region of Paso del Norte is one of the main economic activities in the municipality.

According to the Technological Administration of Innovation and Research (RITA), in the years 2011 to 2013, they crossed an average of more than 725,000 cargo vehicles per year (to the north) through the two border crossings located in the urban spot of Ciudad Juárez (border crossing of Córdova - Las Américas and border crossing Zaragoza-Ysleta). Additionally, the number of crosses from the US and with destination to Mexico (which in the absence of official data) it is estimated that it ranges between $80 \%$ and $100 \%$ of travel cargo vehicles to the US from Mexico. Given these circumstances, it can be assumed that the number of border cargo crossings in both directions of more than 1,200,000 annually [1]. All this has caused the current situation in which cargo vehicles circulate without any control through the streets of the city, which in many cases are not prepared for the circulation of this type of transport. This translates into various negative impacts 
such as: (i) increased traffic jam; (ii) premature degradation of infrastructure, (iii) deterioration of air quality; (iv) increase of noise levels; among others.

Below, Figure 2 and Figure 3 shows the traffic types and volumes of cargo vehicles crossings to the US along the Córdoba-Las Americas and Zaragoza-Ysleta border.

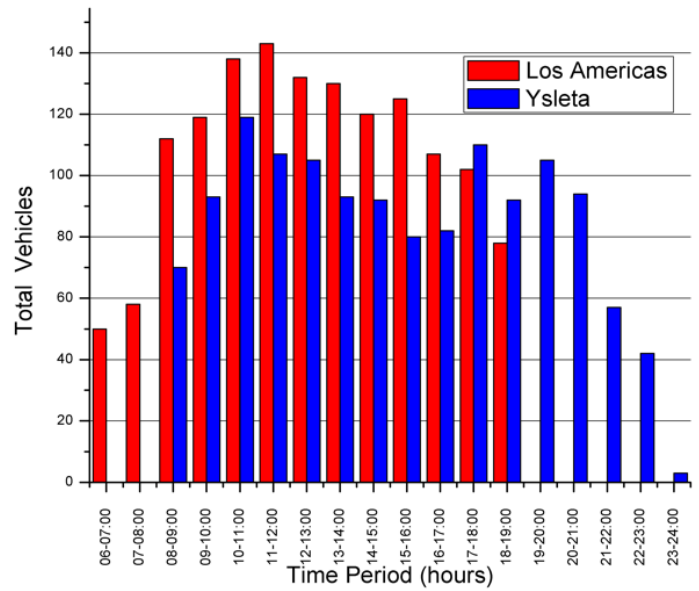

Figure 2. Traffic of Cargo Vehicles using Córdova - Las Américas and Zaragoza - Ysleta de México bridges to the US.

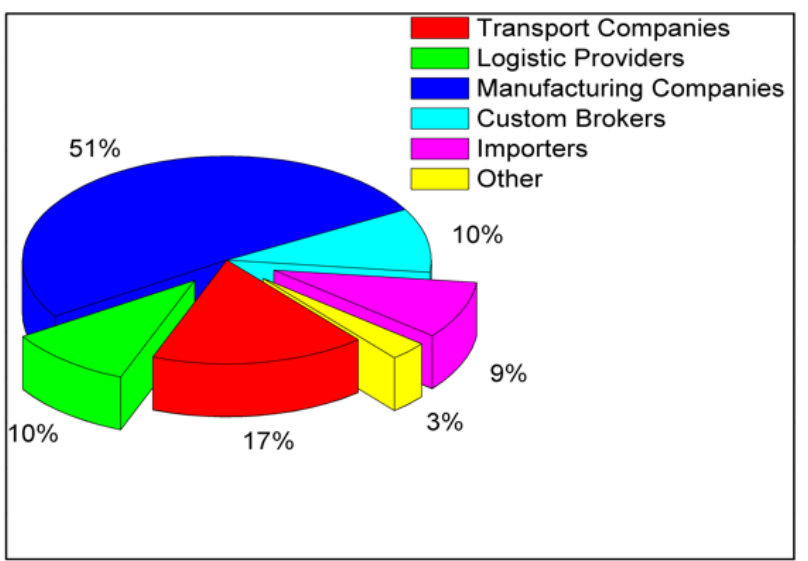

Figure 3. Entity that Determines the Cross-Border Route of Freight Transport.

Geographical location of intersections traffic lights on primary roads of Ciudad Juárez shown on Figure 4, and
Heavy trucks border crossing statistics (1995-2018), and expectation (2019-2030) presented on Figure 5 below.
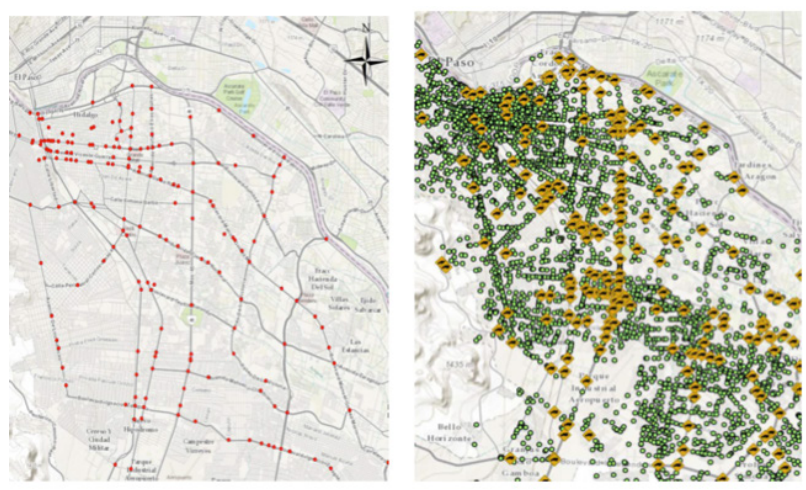

Figure 4. Geographical location of intersection traffic lights (Red) on primary roads in Ciudad Juarez and an Accident Locations (Cars - green, Heavy Tracks - yellow)

Ciudad Juarez is the 3rd most polluted city in the country, and heavy trucks are responsible for $80 \%$ of emissions to the environment. As a key part of the analysis carried out the emissions of freight transport were estimated, and the year 2015 was determined as a baseline.

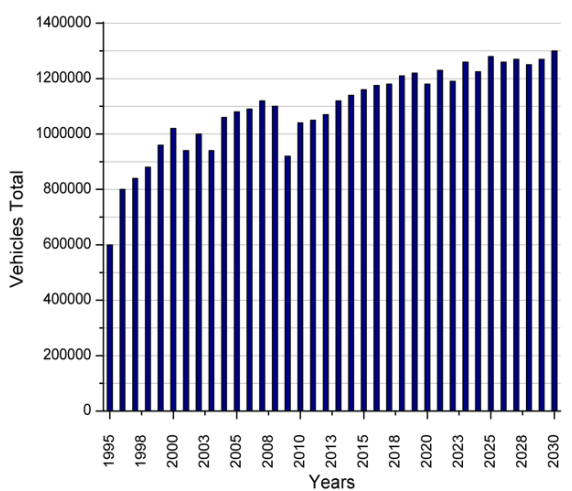

Figure 5. Heavy trucks border crossing statistics (19952018), and expecting (2019-2030) (Data from [1])

The results are shown below on Figure 6, where six atmospheric pollutants were estimated for this purpose: volatile organic compounds (VOCs), carbon monoxide (CO), nitrogen oxides (NOx), carbon dioxide (CO2), sulfur dioxide (SO2) and particles smaller than 10 microns (PM10). All estimate was completed for the time period 
2015 to 2030 and considering the changes in the vehicle fleet and the environmental conditions prospected.

Variation of the pollutants with respect to the base year shows that the contribution is increased by more than $30 \%$, only in the case of SO2, CO2 and NOx is smaller and ranges between $10 \%$ and $15 \%$, it can be seen that freight transport reflects an important contribution situation, compared to private cars that, although they contribute, is not representative to consider within the study.

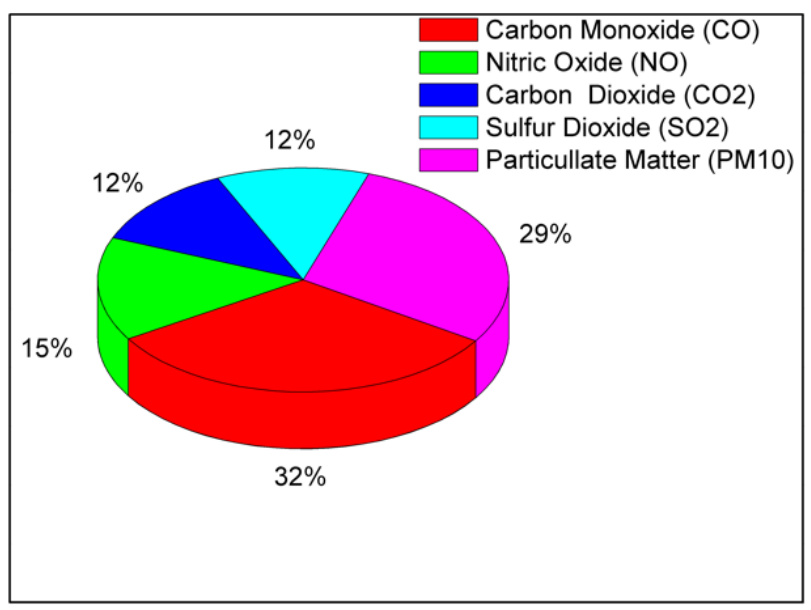

Figure 6. Variations of the contaminating environment pollutants from heavy trucks in Juarez area.

\section{HEAVY TRACKS DRAG REDUCTION DEVICES}

Nowadays, there are a large number of devices to reduce the air drag of heavy trucks and technologies in use and in development. Many of them have been extensively studied, with the performance benefits well documented in the research press. They include roof deflectors, cab side extensions, tail trailers and trailer side skirts. There are following important areas for improvement of the aerodynamics of tractor-trailers under the freeway conditions:

- Vehicle streamlining

- Air flow control:

about the gap between tractor and trailer; under the trailer; at the rear (end) of the trailer.
Considering of some previous and recent technologies, it is predicted [2] that above-mentioned improvements can lower fuel consumption of heavy trucks up to $15 \%$ in the period of last five years.

The drag reduction technologies can be divided into two main categories; those mounted on the tractor and those mounted on the trailer. As stated Leuschen, Cooper [3] et al., there are three to four times as many trailers in operation, as there are tractors. Like the vast majority of additional drag reduction devices usually installed on a trailer, the industry is reluctant to use additional devices, because there are some distinctions between tractor owners (and operators) and trailer owners. Because of increasing trailer's purchase costs, there is little motivation of trailer manufacturers for adoption these devices improving aerodynamics. The payback time period of attachments will be much shorter for devices on a trailer, which will affect the speed of implementation of such technologies in transport industry. Therefore, tractor devices and technologies are likely to be adopted earlier.

When evaluating potential fuel economy on trailers, it's important to understand the context in which any measurements or evaluations have been made. Results, especially those based on road tests may be biased depending on conditions the vehicle and the environment in which they were tested.

Most of the previous researches were complete on very specific options of tractor-trailers combinations. The recent researches study the most common commercially available resistance reduction devices on various combinations of tractor-trailer units. In particular, there are few studies of negative effects that may occur due to cab roof fairings and side extensions when used with certain combinations of trailers [4]. Most recent second-generation research technologies typically perform drag reduction or fuel economy assessments using streamlined form of a new generation tractor. Truckers often prefer older boxing style tractors with many appendages, lights and without air deflectors. 
As noted above, four critical areas are identified for applying resistance reduction technologies. Initially, a general list of concepts was developed based on several references [2], [5], [6], [7], [8], [9], [10], [11], [12], [13], [14] [15] that identify technologies and devices that can be the potential for reducing the drag of a tractor with a trailer is estimated.

\section{A. Tractor streamlining}

For the past three decades, tractor optimization by manufacturers is a motivation force in the development of tractors. Also, any fuel crisis contributed to the development and subsequent market launch of tractors in the next 10-20 years after crisis. As a result, all manufacturers have models of aerial tractors that have been designed with fuel economy in mind, compare to classic tractors with square caps, flat bumpers and large external details such as air filters and exhaust pipes. Streamlined models of tractors significantly decrease aerodynamic drag, compared with the classic style, by about 30\% [5]. Rounding the front surfaces, using roof air deflectors and the use of fairings above the fuel tanks between the steering axle and driving bridges mainly achieve this improvement.

Current efforts to gradually reduce tractor resistance are directed to bumper sections, the underbody and gap between tractor and trailer.

\section{B. Air flow control around the gap of the tractor and trailer} The area immediately behind the tractor and in front of the trailer is defined as a gap between tractor and trailer (Fig. 7).

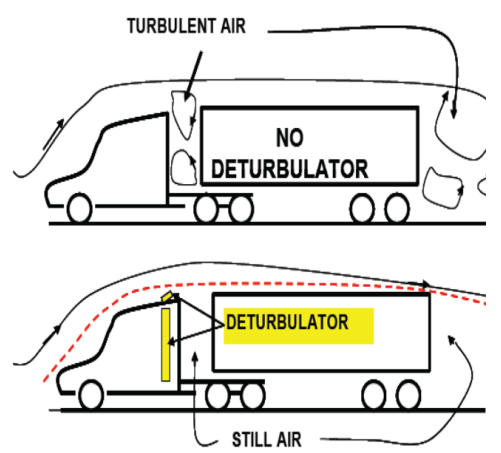

Figure 7. Aerodynamic condition over the gap between tractor and trailer without (up) and with (down) drag reducing devices [18]

The flow behavior in this gap area directly affects pressure in this part of tractor-trailer combination, and significantly increasing the overall (total) drag onto the vehicle [16]. This is the dominant region for which an assessment of wind resistance is required to determine the benefits of drag reducing devices.

To minimize the effect of gap on drag, a complete seal of the clearance will eliminate contribution under crosswind condition. However, due to operational requirements minimum clearance of the gaps between tractor and trailer is required for maneuvering at loading and unloading facilities. Typical these gaps are in range of about 1.0 meter. In [13] was presented that the gap begins to induce significant negative effect on the resistance of the track when it is greater than $0.45 \mathrm{~m}$, and the drag increases by $2 \%$ for every additional $0.25 \mathrm{~m}$. Study by Landman et al. [13] suggested that with the complete elimination of the gap issue, savings will be about $6 \%$ for a typical tractor-trailer. This will be approximately $3 \%$ improvement in fuel consumption at $98 \mathrm{~km} / \mathrm{h}$ (60 mph), as shown in Figure 8 .

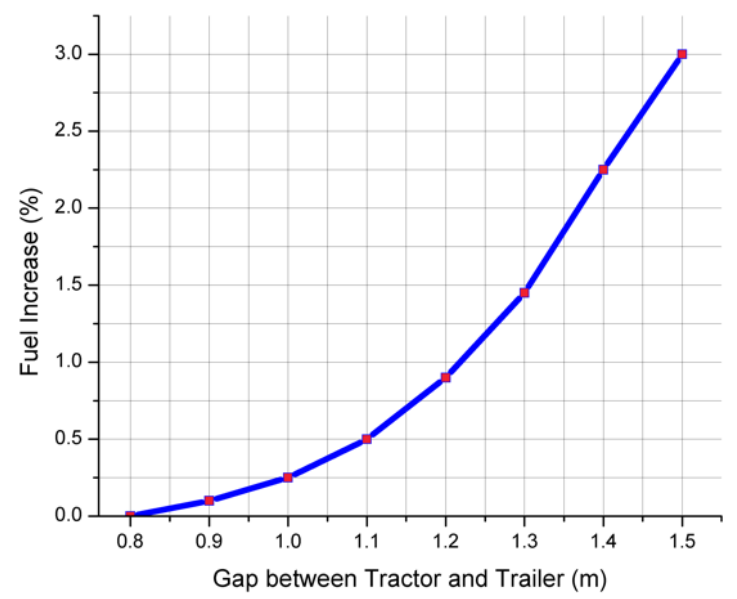

Figure 8. Increase of fuel consumption versus Gap between Tractor and Trailer (Data from 15) 
There are two main types of devices designed to reduce drag in the gap between tractor and trailer. These are tractor side extensions and devices in the gaps.

Side extensions mounted on the tractor extend the rear edge of the cab to prevent flow air to the gap area. The gap splitter (large vertical plate) is a technique often used for trailers. A tractor mounted gap splitter will behave similarly while minimizing implementation costs.

The final technique to reduce the drag associated with the gap between the tractor and trailer is to reduce this gap, but this method is limited by the operational requirements of the minimum clearance.

\section{Airflow control under the trailer}

Like the gap between the tractor and the trailer, an open area under the trailer provides greater drag resistance under crosswind condition. It is important to mention too, that the most efficient way to minimize the air drag under the trailer is to prevent air from entering. Mercedes presented a concept trailer, providing an $18 \%$ reduction in total air drag for European combination of tractor-trailer [17]. Trailer uses air dams, trim panels, side skirts, boat fairings and tail to reduce overall vehicle air drag. The concept is a complete package and does not consist of separate addition components.

\section{Airflow control at the rear of the trailer}

The trailer's underneath is one of the most significant sources of air drag for tractor-trailers combinations. Lower pressure on the front surface of the trailer due to the gap between tractor and trailer, combined with higher air pressure on the front side of the tractor induces and generates aerodynamic force vectoring down.

The pressure difference from high in front to low in back is the main source of air drag for the most tractor-trailer combinations. An increase air pressure in some region of tractor-trailer will equilibrate pressure differential and decrease vehicle total air resistance. Thus, many drag reduction technologies for the trailer are aimed at increasing this backpressure.

\section{CONCLUSION}

Since aerodynamic drag is one of the sources of fuel consumption, it is important to understand its effects on total fuel consumption. At a speed of $80 \mathrm{~km} / \mathrm{h}$, a decrease in resistance of $20 \%$ will contribute to reduction in fuel consumption by about $10 \%$. Consequently, reduction in fuel consumption will reduce contamination of the air by reducing the amount of pollutant elements, which is very stressful environmental, political and social factors.

It was shown that the gap between tractor and trailer begins to have a significant effect on the resistance of the vehicle after it greater than about $0.45 \mathrm{~m}$, while the resistance increases by about $2 \%$ for every $0.25 \mathrm{~m}$ a gap beyond approximately $0.75 \mathrm{~m}$. Studies have shown that, completely addressing the gap problem saves about $6 \%$ on a conventional tractor with a trailer. This will be a roughly $3 \%$ improvement in fuel consumption at $98 \mathrm{~km} / \mathrm{h}$ (60 mph).

Side skirts are preventing air from entering the area under the trailer. Nowadays, these technics have been widely adopted and maybe seen on many tractor-trailers' combinations. The reduction of fuel consumption of 3-7\% has been reported for this technic.

It was also shown that the side underbody boxes reduce drag by $10-15 \%$ and can be used to store equipment that is usually attached to the outside of the tractor or bottom of the trailer. Boxes under the bottom can also be used instead of traditional side guards. However, they increase the weight of the trailer and can also affect the angle of break over as trailers drive through railroad tracks and other obstacles.

Aero-tractor models provide reduction aerodynamic drag, compared with the classic style, on about $30 \%$. This is achieved mainly due to rounding of the front surfaces, using roof air deflectors and the use of fuel tank fairings 
between the steering axle and driving bridges.

\section{REFERENCES}

[1] Technological Administration of Innovation and Research (RITA) https://www.transportation.gov/research-technology

[2] National Academy of Sciences (NAS). 2010. Technologies and Approaches to Reducing the Fuel Consumption of Medium- and Heavy-Duty Vehicles. Committee to Assess Fuel Economy Technologies for Medium- and Heavy-Duty Vehicles. The National Academic Press.

[3] J. Leuschen and K.R. Cooper, Full-Scale Wind Tunnel Tests of Production and Prototype, Second-Generation Aerodynamic Drag-Reducing Devices for Tractor-Trailers, 06CV-222, SAE International, 2006.

[4] H. Martini, B. Bergqvist, L. Hjelm and L. Löfdahl, Aerodynamic Effects of Roof Deflector and Cab Side Extenders for Truck-Trailer Combinations, 2011-012284, SAE International, 2011.

[5] Cooper, K. R. 2004. Commercial Vehicle Aerodynamic Drag Reduction: Historical Perspectives as a Guide. In The Aerodynamics of Heavy Vehicles: Trucks, Buses, and Trains (McCallen, R., Browand, F., and Ross, J., eds.) pp. 9-28, Springer, New York.

[6] Leuschen, J., Cooper, K. R. 2006. Full-Scale Wind Tunnel Tests of Production and Prototype, Second-Generation Aerodynamic Drag-Reducing Devices for Tractor-Trailers. SAE Paper No. 2006-01-3456.

[7] Leuschen, J., Cooper, K. R. 2006. Summary of FuII-Scale Wind Tunnel Tests of Aerodynamic Drag-Reducing Devices for Tractor-Trailers. Lake Tahoe.

[8] Salari, K. 2011. DOE's Effort to Reduce Truck Aerodynamic Drag through JointExperiments and Computations - DOE Annual Merit Review, Project ID \# VSS006 May 9-13, 2011 (Presentation). Document found at http://www1.eere.energy.gov/vehiclesandfuels/pdfs/merit_review_2011/veh_sys_sim/ vss006_salari_2011_o.pdf. Accessed January 2012.

[9] Platform for Aerodynamic Road Transport, found at http://www.part20.eu/en/ Accessed January 2012.
[10] Salari, K. Ortega, J. 2010. Aerodynamic Design Criteria for Class 8 Heavy Vehicles Trailer Base Devices to Attain Optimum Performance. Lawrence Livermore National Laboratory Report No. LLNL-TR-464265.

[11] Patten, J; Poole G; Mayda, W; Trailer Boat Tail Aerodynamic and Collision Study; NRC-CSTT; CSTTHVC-TR-169; March 2010.

[12] Sinha, S. K. 2008. Improving Fuel Efficiency of Tractor Trailer Trucks with Deturbulator Aero-Drag Reduction. SAE Paper No. 2008-01-2602.

[13] Landman, D., Wood, R., Seay, W., Bledsoe, J. 2009. Understanding Practical Limits to Heavy Truck Drag Reduction. SAE Paper No. 2009-01-2890.

[14] System Drag Reduction (SDR). Road Tech for Saving and Ecology. Document found at http://sdr-sys. com/archivos/Presentation.SDR-2010-2011.pdf Accessed

[15] L. Hjelm and B. Bergqvist, European Truck Aerodynamics - A Comparison Between Conventional and CoE Truck Aerodynamics and a Look into Future Trends and Possibilities, The Aerodynamics of Heavy Vehicles II: Trucks, Buses, and Trains, Volume 41, 2009.

[16] P. Castellucci and K. Salari, Computational Simulation of Tractor-Trailer Gap Flow with Drag-Reducing Aerodynamic Devices, 2005-01-3625, SAE International, 2005.

[17] Daimler, 2011. Aero trailer design study from Mercedes-Benz: drastically cutting wind resistance and fuel consumption of semitrailer tractors. Found at http://media.daimler.com/deeplink?cci=2095425 Accessed January 2012.

[18] S.K. Sinha, Improving Fuel Efficiency of Tractor Trailer Trucks with Deturbulator Aero-Drag Reduction, 2008-01-2602, SAE International, 2008 